\title{
Is investigation of patients with haemoptysis and normal chest radiograph justified?
}

\author{
M Thirumaran, R Sundar, I M Sutcliffe, D C Currie
}

\section{See Editorial, p 829}

Dewsbury and District Hospital, Mid Yorkshire Hospitals NHS

Trust, Dewsbury, West

Yorkshire, UK

Correspondence to:

Dr D C Currie, Department of Respiratory Medicine, Dewsbury and District Hospital, Mid

Yorkshire Hospitals NHS Trust,

Halifax Road, Dewsbury, West

Yorkshire WF13 4HS, UK; David.

Currie@midyorks.nhs.uk

Received 28 September 2008 Accepted 23 April 2009 Published Online First 19 May 2009

\section{UN IOCKED}

This paper is freely available online under the BMJ Journals unlocked scheme, see http:// thorax.bmj.com/info/unlocked.dtl

\section{ABSTRACT}

Background: Haemoptysis is a common clinical symptom. A small proportion of patients present with haemoptysis and normal chest radiograph. The investigation strategy for this group of patients is unclear. The aim of this study is to see whether further investigations for this group of patients are justified.

Methods: A retrospective analysis was conducted of consecutive patients presenting with haemoptysis and normal chest radiograph over a period of 56 months irrespective of their smoking status. These patients were investigated by CT of the thorax and fibreoptic bronchoscopy. Results: 275 episodes of haemoptysis with normal chest radiograph were investigated further in 270 patients $(60 \%$ males). The median age was 60 years. Twenty-six patients were diagnosed to have respiratory tract malignancies (larynx, 1; trachea, 1; lung, 22; carcinoid, 1; and leiomyoma, 1). Eight (31\%) of the 26 patients with respiratory tract malignancy had radical treatment. Fibreoptic bronchoscopy was diagnostic of cancer in 14 (54\%) of the 26 patients with malignancy. CT of the thorax was suggestive of cancer in $24(96 \%)$ of the 25 patients with malignancy.

Conclusion: It is concluded that further investigation of haemoptysis in smokers is justified regardless of the amount or frequency of haemoptysis based on a 9.6\% rate of malignancy in this consecutive series. It is recommended that these patients are investigated with CT of the thorax followed by fibreoptic bronchoscopy.

Haemoptysis is a common and worrying clinical symptom. It is potentially life threatening and warrants further investigation. Haemoptysis can be due to varying aetiologies including lung cancer. ${ }^{1}$ The optimal strategy for investigating patients with haemoptysis and normal chest radiograph (CXR) is unclear. Doctors tend to investigate these patients differently.

The prognosis for lung cancer remains poor, with 5 -year survival figures of $4-12 \%$ worldwide. ${ }^{2}{ }^{3}$ The prospects for changing this are limited by a number of factors including, most notably, the late presentation of patients with advanced disease and the lack of convincing evidence for screening asymptomatic individuals for lung cancer. Early diagnosis of lung cancer is crucial to allow curative resection. Further investigations of patients with haemoptysis and normal CXR may lead to early diagnosis.

In this retrospective study we analysed a group of patients with haemoptysis and normal CXR to see whether further investigations were justified.

\section{METHODS}

We conducted a retrospective analysis of consecutive patients presenting with haemoptysis and normal CXR to Dewsbury and District Hospital, West Yorkshire, UK between May 2001 and December 2005. The catchment population of our hospital is 175000 .

All patients presenting with haemoptysis and a normal CXR were investigated further in line with local guidance irrespective of their smoking status, age, or quantity or frequency of haemoptysis. The UK national guidelines ${ }^{4}$ for management of lung cancer recommend urgent CXR for patients presenting with haemoptysis. In our local policy for referral and management of lung cancer for general practitioners (GPs) and general physicians, urgent referral to chest physicians was advised for all patients presenting with haemoptysis regardless of the CXR result. The patients were either referred from primary care locally or from secondary care in our hospital.

The patients were identified from the urgent suspected lung cancer referrals database and our fibreoptic bronchoscopy (FOB) database. Patients with abnormal CXR were excluded. The CXR should have been reported normal by a radiologist or documented to be normal in medical notes by a chest physician. The outpatient CXRs are reported by our radiologists as a standard practice.

These patients were routinely investigated further by CT of the thorax, FOB as well as history, clinical examination and blood investigations. The standard CT procedure in our institution for lung cancer staging during the study period was contrast-enhanced contiguous $5 \mathrm{~mm}$ sections from lung apices to the liver and adrenal glands. FOB is performed either by the chest physician or by supervised trainees. From the clinical records the following variables were collected: age, sex, smoking history, comorbidities, symptoms (eg, chest pain, weight loss), quantity/nature (streak, teaspoonful, tablespoonful), frequency and duration of haemoptysis (once only, recurrent lasting up to or more than 1 week), history of chronic sputum production when available and the final diagnosis based on clinical, radiology and histology findings.

\section{RESULTS}

A total of 275 episodes of haemoptysis with normal CXR were investigated further in 270 patients (60\% males). The median age was 60 years (interquartile range 22 years); $10 \%$ were under the age of 40 . Ninety percent of these patients were either active smokers (156) or ex smokers (90). The details of the nature and frequency of haemoptysis are as listed in table 1. The details of associated symptoms and comorbidities are listed in table 2. FOB was performed in 269 patients (98\%). CT was performed in 257 patients 
Table 1 Nature and frequency of haemoptysis in patients

\begin{tabular}{llllll}
\hline & \multirow{2}{*}{$\begin{array}{l}\text { No. of } \\
\text { Nature of } \\
\text { paemoptysients } \\
\text { (percentage) }\end{array}$} & $\begin{array}{l}\text { Oncequency of haemoptysis } \\
\text { only }\end{array}$ & $\begin{array}{l}\text { Less than a } \\
\text { week }\end{array}$ & $\begin{array}{l}\text { One week } \\
\text { or more }\end{array}$ & $\begin{array}{l}\text { Not } \\
\text { known }\end{array}$ \\
\hline Streaks & $165(60 \%)$ & 54 & 85 & 23 & 3 \\
Teaspoonful & $52(18.9 \%)$ & 10 & 33 & 8 & 1 \\
Tablespoonful & $39(14.2 \%)$ & 10 & 24 & 4 & 1 \\
Egg cup full & $1(0.4)$ & 1 & 0 & 0 & 1 \\
Not specified & $18(6.5 \%)$ & 8 & 2 & 5 & 3 \\
\hline
\end{tabular}

(94\%). The results of FOB and CT are cross-tabulated in table 3. Diagnoses of respiratory tract neoplasias and other diagnoses achieved are as listed in tables 4 and 5 , respectively.

Overall, $26(9.6 \%)$ patients were diagnosed to have respiratory tract malignancy. Nine $(35 \%)$ of the 26 patients with repiratory tract malignancy were suitable for radical treatment. Eight (31\%) of the 26 patients with respiratory tract malignancy had radical treatment. One patient with T2NOM0 non-small cell lung cancer refused radical treatment. Six patients had curative surgical resection (lung, 5; trachea, 1), one had radical radiotherapy and one had photodynamic therapy (PDT). Four other patients underwent surgical resection for probable malignancy, but the final histology showed suture granuloma (1), aspergilloma (1) and organising pneumonia (2). Two patients were diagnosed to have papillary carcinoma of the thyroid and lymphoma incidentally. One patient required embolisation for life-threatening haemoptysis of unknown cause.

Nineteen patients were diagnosed to have malignancy in the 28 patients with bronchoscopy findings suspicious of malignancy (lung, 17; trachea, 1; and larynx, 1). Follow-up bronchoscopies were required in one patient and lung cancer was diagnosed only on the third occasion. Two patients with squamous metaplasia had serial autofluorescence bronchoscopies which ruled out malignancy. FOB was diagnostic of cancer in $14(54 \%)$ of the 26 patients with respiratory tract malignancy (one patient declined FOB).

Twenty-four cancers were diagnosed in the 30 patients who had CT findings suspicious of cancer. Among the 57 patients with abnormal CT scan not suggestive of malignancy, 30 did show unsuspected pulmonary pathology to explain the haemoptysis (bronchiectasis, 16; pneumonia, 11; leiomyoma, 1; pulmonary embolism and bronchiectasis, 1; tuberculosis, 1). The patient with laryngeal carcinoma did not have a CT due to the suspicion of laryngeal cancer at bronchoscopy which was later confirmed by the Ear, Nose and Throat (ENT) surgeons. CT was suggestive of cancer in 24 (96\%) of the 25 patients with

Table 2 Associated symptoms and co-morbidities in patients

\begin{tabular}{lc}
\hline & No. of patients (percentage) \\
\hline Symptoms & \\
Weight loss & $11(4 \%)$ \\
Chest pain & $11(4 \%)$ \\
Cough & $195(71 \%)$ \\
Purulent sputum & $41(15 \%)$ \\
Comorbidities & \\
Ischaemic heart disease & $30(10.9 \%)$ \\
Chronic obstructive pulmonary disease & $32(11.6)$ \\
Hypertension & $15(5.4 \%)$ \\
Asthma & $12(4.3 \%)$ \\
Diabetes & $9(3.2 \%)$ \\
\hline
\end{tabular}

Table 3 Cross-tabulation of CT and bronchoscopy results in patients

\begin{tabular}{lrrrr}
\hline & \multicolumn{3}{c}{ CT scan results } & \\
\cline { 2 - 5 } & Normal & ?Malignancy & $\begin{array}{l}\text { Benign } \\
\text { changes }\end{array}$ & Not done \\
\hline Bronchoscopy results & 158 & $11^{*}$ & 49 & 15 \\
Normal & 0 & 13 & 1 & 0 \\
?Malignancy $\dagger$ & 4 & 6 & 3 & 1 \\
?Malignancy & 4 & 0 & 4 & 0 \\
Benign changes & 3 & $1 \S$ & 1 & 0 \\
Not done & & & &
\end{tabular}

Data are presented as numbers. Bronchoscopy, $\mathrm{n}=269 ; \mathrm{CT}, \mathrm{n}=257$.

*Final diagnosis of malignancy made in 10 patients.

†Confirmed to be malignancy in bronchoscopy samples.

\#Benign pathology diagnosed from bronchoscopy samples.

$\S$ Clinical diagnosis of lung malignancy.

respiratory tract malignancy (the patient with laryngeal cancer was referred to the ENT team after bronchoscopy without CT). Investigations carried out following $\mathrm{CT}$ and $\mathrm{FOB}$ in 16 patients (20 procedures) are listed in table 6.

Among the 26 patients diagnosed to have respiratory tract malignancy in our study, 22 were males $(85 \%)$ and smokers with an average of 38 pack-years. The median age of these patients was 69 years with age range 33-84 years. Thirteen of these patients reported only streak(s) of haemoptysis. Thirteen patients had only one or two episodes of haemoptysis in total prior to presentation. Seventeen of these patients had haemoptysis lasting less than a week. Only 5 of the 26 patients had recurrent haemoptysis of at least a tablespoonful.

\section{DISCUSSION}

In this retrospective study $9.6 \%$ of patients were diagnosed to have respiratory tract malignancy. In spite of our local policy, all the patients who presented with haemoptysis may not have been referred to us, leading to selection bias. Previous studies found a $0-16 \%$ cancer detection rate in patients presenting with haemoptysis and normal CXR. ${ }^{5-10}$

Haemoptysis is the presenting symptom in up to $19 \%$ of the patients with lung cancer. ${ }^{11}$ Poe et al found that coughing up > $30 \mathrm{ml}$ of blood increased the diagnostic yield. ${ }^{12}$ In our study only 5 patients with lung cancer had a tablespoonful, recurrent haemoptysis, and more than half of the patients had only streak(s) with infrequent episodes of haemoptysis lasting less than a week. Fidan et al reported in a retrospective analysis of patients presenting with haemoptysis that just over $40 \%$ of patients with lung cancer presented with mild and nonrecurrent haemoptysis. ${ }^{13}$

Some studies looked at whether patients above a particular age should be investigated. Sood et al analysed all the studies published so far and concluded that age above 50, male sex and smokers of 40 pack-years had the highest predictive value for bronchogenic carcinoma. ${ }^{14}$ In contrast, Cortese et al reported radiologically occult lung cancer in $5.5 \%$ of patients who were $<50$ years old..$^{15}$ A primary care cohort study reported higher

Table 4 Respiratory tract neoplasias diagnosed

\begin{tabular}{lr}
\hline Non-small cell carcinoma & 20 \\
Small cell carcinoma & 2 \\
Laryngeal carcinoma & 1 \\
Tracheal paraganglioma & 1 \\
Carcinoid & 1 \\
Leiomyoma & 1
\end{tabular}

Data are presented as numbers $(n=26)$ 
Table 5 Final diagnosis for each episode of haemoptysis

\begin{tabular}{lr}
\hline Acute bronchitis & 174 \\
Respiratory tract malignancies & 26 \\
Bronchiectasis & 20 \\
Pneumonia & 16 \\
Unexplained & 16 \\
Epistaxis & 5 \\
Tuberculosis & 4 \\
Pulmonary fibrosis & 2 \\
Organising pneumonia & 2 \\
Squamous metaplasia & 2 \\
Lymphoma & 1 \\
Carcinoma of the thyroid & 1 \\
Chondroma & 1 \\
Hamartoma & 1 \\
Pulmonary emboli & 1 \\
Sarcoidosis & 1 \\
Suture granuloma & 1 \\
Aspergilloma & 1 \\
\hline
\end{tabular}

Data are presented as numbers $(n=275)$.

positive predictive value for cancer in patients aged above 55 years when they present with haemoptysis irrespective of CXR appearance. ${ }^{16}$ The median age of patients with lung cancer in our study is 69 years with male predominance (85\%).

Both FOB and CT have definite important roles in evaluating haemoptysis in patients with abnormal CXR for bronchogenic carcinoma. A lung cancer detection rate of up to $21 \%$ with bronchoscopy alone in patients with haemoptysis and normal CXR has been reported. ${ }^{17-20}$ Prospective studies by Tak et al and Haro et al indicate that $\mathrm{FOB}$ and $\mathrm{CT}$ are complementary, irrespective of CXR findings. ${ }^{6} 2122$ Even though FOB is a relatively straightforward procedure it still carries a small risk.

In a long-term outcome study of patients with haemoptysis of unknown aetiology Herth et al reported that $6 \%$ of patients developed lung cancer over a mean follow-up period of 6.6 years. ${ }^{23}$ Santiago et al reported $4 \%$ of patients developing lung cancer over a 6-year period when the initial investigations were inconclusive..$^{24}$ All these patients were smokers and $>40$ years of age. In our study, one patient developed lung cancer after a follow-up period of 20 months. The mean follow-up period in our study population was 36 months.

As far as we are aware, this study reports the largest group of consecutive patients with haemoptysis and normal CXR who were investigated with CT and FOB. Our study demonstrates the importance of investigating such patients. However, our study is retrospective and the characteristics of the patient population prevent us from making recommendations with respect to non-smokers, females or younger people.

\section{CONCLUSION}

Haemoptysis is a valuable diagnostic clue to resectable lung cancer. More frequently haemoptysis is likely to be secondary to benign pulmonary pathology. Bronchoscopy is invasive; radiation is a safety concern of CT, particularly in young people. CT has the advantage of being more sensitive in diagnosing distant bronchial and parenchymal abnormalities, but FOB is better in evaluating mucosal abnormalities and providing material for pathological diagnosis. CT or bronchoscopy could fail to detect abnormalities when the other modality did, as seen in this study. Even though CT and bronchoscopy are complementary, $\mathrm{CT}$ is more likely to detect abnormalities to explain the cause of haemoptysis.
Table 6 Investigations following CT and fibreoptic bronchoscopy

\begin{tabular}{lc}
\hline CT-guided biopsy & 1 \\
Follow-up CT & 10 \\
Follow-up bronchoscopy & 4 \\
Autofluorescence bronchoscopy & 2 \\
Video-assisted thoracoscopy & 1 \\
Mediastinoscopy & 2 \\
\hline
\end{tabular}

Data are presented as numbers $(n=20)$.

We conclude that further investigation of haemoptysis in smokers with a normal CXR is justified regardless of the amount or frequency of haemoptysis based on a $9.6 \%$ rate of malignancy in our consecutive series. We recommend that these patients are investigated with CT followed by bronchoscopy.

Competing interests: None.

Provenance and peer review: Not commissioned; externally peer reviewed.

\section{REFERENCES}

1. Hamilton W, Peters TJ, Round A, et al. What are the clinical features of lung cancer before the diagnosis is made? A population based case-control study. Thorax 2005;60:1059-65.

2. Makitaro R, Paakko P, Huhti E, et al. Prospective population-based study on the survival of patients with lung cancer. Eur Respir J 2002;19:1087-92.

3. Joslin C, Rider L, eds. Cancer in Yorkshire. In: Cancer Registry Special Report Series No. 1, Lung Cancer. Yorkshire Cancer Organisation, 1995.

4. National Institute for Health and Clinical Excellence. Lung cancer: the diagnosis and treatment of lung cancer. London: NICE, 2005.

5. Yin BY. [Bronchoscopic evaluation of 390 cases of hemoptysis without definite abnormality on the chest roentgenogram]. Zhonghua Jie He He Hu Xi Za Zhi 1990;13:44.

6. Tak S, Ahluwalia G, Sharma SK, et al. Haemoptysis in patients with a normal chest radiograph: bronchoscopy-CT correlation. Australas Radiol 1999;43:451-5.

7. Zavala DC. Diagnostic fibreoptic bronchoscopy: techniques and results of biopsy in 600 patients. Chest 1975;68:12-9.

8. Heaton RW. Should patients with haemoptysis and a normal chest X-ray be bronchoscoped? Postgrad Med J 1987;63:947-9.

9. Laurent F, Martins M, Sauty A. [Hemoptysis: methods of localization]. Rev Med Suisse 2005;1:2659-63.

10. Lederle FA, Nichol KL, Parenti CM. Bronchoscopy to evaluate hemoptysis in older men with nonsuspicious chest roentgenograms. Chest 1989;95:1043-7.

11. Hirshberg B, Biran I, Glazer M, et al. Hemoptysis: etiology, evaluation, and outcome in a tertiary referral hospital. Chest 1997;112:440-4.

12. Poe RH, Israel RH, Marin MG, et al. Utility of fibreoptic bronchoscopy in patients with hemoptysis and a nonlocalizing chest roentgenogram. Chest 1988;93:70-5.

13. Fidan A, Ozdogan S, Oruc 0, et al. Hemoptysis: a retrospective analysis of 108 cases. Respir Med 2002;96:677-80.

14. Sood R, Mukhopadhyaya S. Approach to a patient with haemoptysis and a normal chest X-ray. J Indian Acad Clin Med 2002;3:14-22.

15. Cortese DA, Pairolero PC, Bergstralh EJ, et al. Roentgenographically occult lung cancer. A ten-year experience. J Thorac Cardiovasc Surg 1983;86:373-80.

16. Jones R, Latinovic R, Charlton J, et al. Alarm symptoms in early diagnosis of cancer in primary care: cohort study using General Practice Research Database. BMJ 2007; 334:1040

17. Jackson CV, Savage PJ, Quinn DL. Role of fibreoptic bronchoscopy in patients with hemoptysis and a normal chest roentgenogram. Chest 1985;87:142-4.

18. Jindal SK, Gilhotra R, Behera D. Fibreoptic bronchoendoscopic examination in patients with haemoptysis and normal chest roentgenogram. J Assoc Physicians India 1990;38:548-9

19. Kallenbach J, Song E, Zwi S. Haemoptysis with no radiological evidence of tumour - the value of early bronchoscopy. S Afr Med J 1981;59:556-8.

20. Kaminski J. [Frequency and causes of hemoptysis and role of bronchoscopy in patients with normal chest roentgenogram hospitalized in the Department of Physiopneumonology Silesian Medical University in the years 1961-1996]. Pneumonol Alergol Pol 2001;69:663-8.

21. Haro M, Jimenez J, Tornero A, et al. [Usefulness of computerized tomography and bronchoscopy in patients with hemoptysis. Analysis of 482 cases]. An Med Interna 2002; 19:59-65.

22. Haro Estarriol M, Vizcaya Sanchez M, Jimenez Lopez J, et al. [Etiology of hemoptysis: prospective analysis of 752 cases]. Rev Clin Esp 2001;201:696-700.

23. Herth $\mathbf{F}$, Ernst $A$, Becker HD. Long-term outcome and lung cancer incidence in patients with hemoptysis of unknown origin. Chest 2001;120:1592-4.

24. Santiago SM, Lehrman S, Williams AJ. Bronchoscopy in patients with haemoptysis and normal chest roentgenograms. Br J Dis Chest 1987;81:186-8. 